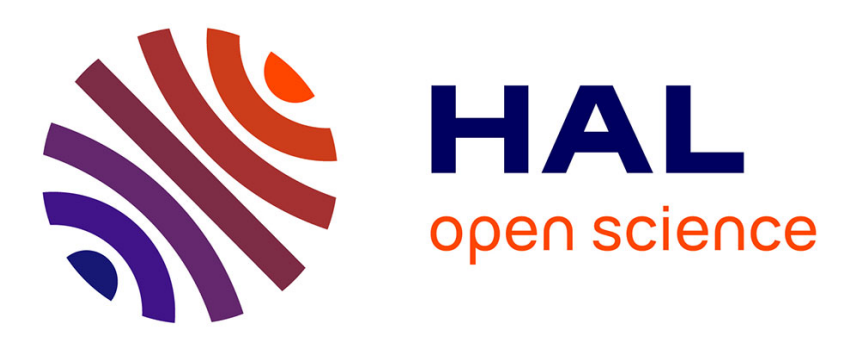

\title{
Influence de conditions culturales différentes sur l'évolution de la RuBisCO, de la photosynthèse nette et de la production de quelques espèces (blé, colza, féverole, soja, tournesol) (1)
}

Enrique Martinez, Noël Gelfi, Andrée Bouniols, Gérard Cavalie

\section{To cite this version:}

Enrique Martinez, Noël Gelfi, Andrée Bouniols, Gérard Cavalie. Influence de conditions culturales différentes sur l'évolution de la RuBisCO, de la photosynthèse nette et de la production de quelques espèces (blé, colza, féverole, soja, tournesol) (1). Agronomie, 1987, 7 (9), pp.667-676. hal-00885040

\author{
HAL Id: hal-00885040 \\ https://hal.science/hal-00885040
}

Submitted on 1 Jan 1987

HAL is a multi-disciplinary open access archive for the deposit and dissemination of scientific research documents, whether they are published or not. The documents may come from teaching and research institutions in France or abroad, or from public or private research centers.
L'archive ouverte pluridisciplinaire HAL, est destinée au dépôt et à la diffusion de documents scientifiques de niveau recherche, publiés ou non, émanant des établissements d'enseignement et de recherche français ou étrangers, des laboratoires publics ou privés. 


\title{
Influence de conditions culturales différentes sur l'évolution de la $\mathrm{RuBisCO}$, de la photosynthèse nette et de la production de quelques espèces (blé, colza, féverole, soja, tournesol) (1)
}

\author{
Enrique MARTINEZ, Noël GELFI (*), Andrée BOUNIOLS $(*)$ \& Gérard CAVALIE \\ Centre de Physiologie végétale associé au C.N.R.S., Université Paul Sabatier, 118, route de Narbonne, \\ F 31062 Toulouse Cedex \\ (*) I.N.R.A., Station d'Agronomie, Centre de Recherches de Toulouse, B.P. 27, F 31326 Castanet-Tolosan
}

RÉSUMÉ

\begin{abstract}
L'étude présentée tente de préciser l'influence de la mise en œuvre d'itinéraires techniques différents (fertilisation, irrigation, traitements phytosanitaires, ...) sur la teneur et l'activité carboxylasique de la RuBisCO, ainsi que sur la photosynthèse nette, de diverses espèces végétales : blé, colza, féverole, soja, tournesol.

Il y a souvent peu de différences dans les paramètres étudiés entre les intensifications moyenne et forte mais celles-ci se distinguent de l'intensification faible. Ceci se traduit par des teneurs en azote foliaire, par une activité carboxylasique de la RuBisCO et par une activité photosynthétique plus élevées dans les intensifications moyenne et forte. Par contre, la teneur en RuBisCO est peu influencée par les différents traitements appliqués. En ce qui concerne la teneur en protéines solubles, le niveau d'intensification a eu un effet plus marqué chez le colza que chez les autres végétaux. D'autre part, chez toutes les espèces, l'activité photosynthétique diminue au moment de la floraison.

Des corrélations positives entre la photosynthèse nette, l'activité RuBisCO et le rendement obtenu ont été mises en évidence à certains stades physiologiques : début f́loraison (blé, colza) ou fin floraison début formation du fruit (féverole, soja, tournesol).
\end{abstract}

Mots clés additionnels : Système de culture, azote des feuilles, protéines solubles, Triticum aestivum L., Brassica napus $L$., Vicia faba $L$., Glycine max. (L.) Merr., Helianthus annuus $L$.

Effect of different culture conditions on ribulose bisphosphate carboxylase/oxygenase (RuBisCO), on net photosynthesis and on yield of several crop species (wheat, rape, fieldbean, soybean, sunflower).

The present report deals with the effects of management (fertilization, irrigation, fungicides, herbicides...) on the amount and activity of RuBisCO, as well as on the net photosynthesis of different plant species : wheat, rape, fieldbean, soybean, sunflower. For the parameters studied, there was little difference between treatments of high and medium input levels, but distinguishable differences with the low input level. These differences in high and medium levels of inputs resulted in high leaf nitrogen content, and in increases in RuBisCO activity and photosynthetic activity, while the amount of $\mathrm{RuBisCO}$ remained constant for all treatments. The levels inputs modified the amount of soluble proteins in rape to a greater extent than in the other species studied. In addition, photosynthetic activity in all species decreased at flowering. A positive correlation between net photosynthesis, RuBisCO activity and yield was observed at certain physiological stages : early flowering (wheat, rape) or late flowering-early fruit set (fieldbean, soybean, sunflower).

Additional key words : Cropping systems, leaf nitrogen, soluble proteins, Triticum aestivum L., Brassica napus $L$., Vicia faba $L$., Glycine max. (L.) Merr., Helianthus annuus $L$.

(1) Ce travail a été réalisé dans le cadre d'un stage doctoral, effectué à l'Université Paul Sabatier par E. MARTineZ (Ministerio de Agricultura, Instituto Colombiano Agropecuario, ICA, Bogota, Colombia). 
Influencia de diferentes condiciones culturales sobre la evolucion de la RuBisCO, de la fotosintesis neta y en la produccion de algunas especies (trigo, colza, haba, soya, girasol).

El estudio presentado trata de precisar la influencia, sobre el contenido y la actividad carboxilasica de la $\mathrm{RuBisCO}$, asi como sobre la fotosintesis neta, de la utilization de diversas practicas de cultivo en diferentes especies vegetales : trigo, colza, haba, soya, girasol.

Hay a menudo pocas diferencias en los parametros estudiados entre la niveles de tecnologia promedia y alta, pero ellos se distinguen de los niveles de tecnologia baja. Esto se traduce en contenidos de nitrogeno foliar, actividad carboxilasica de la RuBisCO y actividad fotosintetica mas elevados en los niveles de tecnologia promedia y alta. Por el contrario, hay poca influencia de los diferentes tratamientos aplicados sobre el contenido en $\mathrm{RuBisCO}$. En lo relacionado con el contenido en proteinas solubles, el nivel de la tecnologia tuvo un efecto mas sobre-saliente en la colza que en las otras especies.

Ademas, en todas las especies, la actividad fotosintetica disminuye al momento de la floracion.

Se observo correlaciones positivas entre la fotosintesis neta, la actividad de la RuBisCO y el rendimiento, en ciertos estados fisiologicos : inicio de la floracion (trigo, colza) comienzo de la formacion del fruto (haba, soya, girasol).

Palabras claves adicionales : Sistemas de cultivo, nitrogeno foliar, proteinas solubles, Triticum aestivum $L$., Brassica napus $L$., Vicia faba $L$., Glycine max. (L.) Merr., Helianthus annuus $L$.

\section{ABRÉVIATIONS}

RuBisCO = ribulose-1,5-bisphosphate-carboxylase/ oxygénase ;

Tris = trishydroxyméthylamino-méthane ;

EDTA = acide éthylènediaminotétraacétique ;

PEG = polyéthylène glycol ;

DTT $=$ dithiothréitol.

\section{INTRODUCTION}

Parmi les facteurs susceptibles d'influencer négativement la croissance et le rendement des espèces cultivées, on cite généralement les températures extrêmes, la privation d'eau, l'insuffisance d'éléments nutritifs, les attaques parasitaires ; leur action s'exerce en particulier sur l'activité photosynthétique. La fixation de l'anhydride carbonique est assurée, exclusivement, chez les plantes de type $\mathrm{C} 3$, par une enzyme chloroplastique, la ribulose 1-5 biphosphate carboxylase oxygénase (RuBisCO, E.C. 4.1.1.39), protéine la plus abondante dans le monde végétal (Ellis, 1979).

Une corrélation entre l'activité carboxylasique de la RuBisCO et le taux de photosynthèse nette a été signalée par différents auteurs (HESKETH et al., 1981; COURTIADE, 1983 ; MAKINO et al., 1983 ; TORISKY \& SERVAITES, 1984).

Toutefois, chez le blé, la teneur en RuBisCO par unité de surface foliaire peut varier selon les génotypes (PYKE \& LEECH, 1985) ; des différences génotypiques de l'activité carboxylasique de la RuBisCO ont également été observées (EVANS \& SEEMAN, 1984). MACHLER \& NOSBERGER (1980) ont montré que les facteurs lumière, teneur en $\mathrm{CO}_{2}$ et température régulent à la fois la photosynthèse et l'activité RuBisCO, et MAKINO et al. (1983) ont souligné que la teneur en RuBisCO pouvait être un facteur limitant de la photosynthèse pendant la croissance des feuilles.

BLANCHET et al. (1986) ont, en outre, mis en évidence que la cinétique de l'assimilation nette est très liée à celle de l'absorption d'azote qui conditionne l'expansion du feuillage et sa teneur en capteurs d'énergie et de $\mathrm{CO}_{2}$.

Dans les expérimentations relatées ici, nous avons tenté de préciser l'influence sur la photosynthèse du couvert, l'activité de la RuBisCO et la teneur en protéines foliaires, de la mise en œuvre d'itinéraires techniques choisis en vue de réaliser des niveaux de rendements différents.

\section{PROTOCOLE EXPÉRIMENTAL}

\section{A. Végétaux et conditions de culture}

Trois cultures d'hiver : blé (Triticum aestivum L. cv. Talent), colza (Brassica napus L. cv. Bienvenu) et féverole (Vicia faba L. cv. Talo), ainsi que 2 cultures d'été : soja (Glycine max. (L.) Merr. cv. Weber, (irrigué) et cv. Kingsoy, (sec) et tournesol (Helianthus annuus L. cv. Topflor), ont été réalisées sur un sol brun alluvial, profond, limono-argileux.

Les semis ont été effectués courant septembre 1984 pour le colza, en novembre de la même année pour le blé et la féverole, et en avril 1985 pour le soja et le tournesol.

L'expérimentation se situe dans le dispositif mis en place à la station d'Agronomie Toulouse-Auzeville (MARTY et al., 1981, 1984a, 1984b) pour l'étude de l'optimisation des systèmes de cultures. Ce dispositif comporte 3 niveaux d'intensification :

- faible: réduction du nombre d'interventions, recherche du meilleur rendement au moindre coût en acceptant quelques risques, cultures non irriguées, fertilisation minimum, traitements phytosanitaires minimum, objectif de rendement : par exemple pour le blé $55 \mathrm{q} / \mathrm{ha}$;

- moyen : itinéraires techniques justifiés par un objectif de rendement moyen ( $70 \mathrm{q} /$ ha pour le blé) au niveau de la rotation culturale, fertilisation légèrement supérieure aux exportations, irrigation aux périodes critiques (quantités d'eau limitées), traitements curatifs contre les parasites ; 
TABLEAU 1

Différenciation des niveaux d'intensification. Differentiation in levels of inputs.

\begin{tabular}{|c|c|c|c|c|c|c|}
\hline \multirow{2}{*}{ Itinéraires techniques } & \multirow{2}{*}{$\begin{array}{c}\text { Niveau } \\
\text { d'intensification }\end{array}$} & \multicolumn{5}{|c|}{ Cultures } \\
\hline & & Blé & Colza & Féverole & Soja & Tournesol \\
\hline $\begin{array}{l}\text { Travail du sol } \\
\text { (nombre d'interventions) }\end{array}$ & $\begin{array}{l}\text { Faible } \\
\text { Moyen } \\
\text { Fort }\end{array}$ & $\begin{array}{l}3 \\
3 \\
3\end{array}$ & $\begin{array}{l}3-4 \\
3-3 \\
3-4\end{array}$ & $\begin{array}{l}2-3 \\
2-3\end{array}$ & $\begin{array}{l}2 \\
2 \\
2\end{array}$ & $\begin{array}{l}2 \\
2 \\
3\end{array}$ \\
\hline $\begin{array}{l}\text { Fertilisation } \\
\mathrm{P}-\mathrm{K}(\mathrm{kg} / \mathrm{ha})\end{array}$ & $\begin{array}{l}\text { Faible } \\
\text { Moyen } \\
\text { Fort }\end{array}$ & $\begin{array}{r}60 \\
115 \\
160\end{array}$ & $\begin{array}{r}35 \\
85 \\
125\end{array}$ & $\begin{array}{l}120 \\
200\end{array}$ & $\begin{array}{r}50 \\
130 \\
160\end{array}$ & $\begin{array}{r}40 \\
100 \\
120\end{array}$ \\
\hline $\begin{array}{l}\text { Fertilisation } \\
\mathrm{N}(\mathrm{kg} / \mathrm{ha})\end{array}$ & $\begin{array}{l}\text { Faible } \\
\text { Moyen } \\
\text { Fort }\end{array}$ & $\begin{array}{r}90 \\
150 \\
210\end{array}$ & $\begin{array}{r}80 \\
120 \\
160\end{array}$ & $\begin{array}{l}0 \\
0\end{array}$ & $\begin{array}{l}0 \\
0 \\
0\end{array}$ & $\begin{array}{r}50 \\
130 \\
170\end{array}$ \\
\hline $\begin{array}{l}\text { Désherbage } \\
\text { (nombre d'interventions) }\end{array}$ & $\begin{array}{l}\text { Faible } \\
\text { Moyen } \\
\text { Fort }\end{array}$ & $\begin{array}{r}0 \\
1-2 \\
1-2\end{array}$ & $\begin{array}{r}1 \\
1 \\
1-2\end{array}$ & $\begin{array}{l}1 \\
1\end{array}$ & $\begin{array}{l}1 \\
2 \\
2\end{array}$ & $\begin{array}{l}2 \\
3 \\
3\end{array}$ \\
\hline $\begin{array}{l}\text { Régulateurs de croissance } \\
\text { (nombre d'interventions) }\end{array}$ & $\begin{array}{l}\text { Faible } \\
\text { Moyen } \\
\text { Fort }\end{array}$ & $\begin{array}{l}0 \\
1 \\
1\end{array}$ & & & & \\
\hline $\begin{array}{l}\text { Protection fongique } \\
\text { (nombre d'interventions) }\end{array}$ & $\begin{array}{l}\text { Faible } \\
\text { Moyen } \\
\text { Fort }\end{array}$ & $\begin{array}{r}0 \\
1-2 \\
2-3\end{array}$ & & $\begin{array}{l}1 \\
1\end{array}$ & & \\
\hline $\begin{array}{l}\text { Protection contre les insectes } \\
\text { (nombre d'interventions) }\end{array}$ & $\begin{array}{l}\text { Faible } \\
\text { Moyen } \\
\text { Fort }\end{array}$ & & $\begin{array}{l}2-3 \\
3-4 \\
3-4\end{array}$ & $\begin{array}{l}1 \\
1\end{array}$ & & \\
\hline $\begin{array}{l}\text { Irrigation } \\
(\mathrm{mm})\end{array}$ & $\begin{array}{l}\text { Faible } \\
\text { Moyen } \\
\text { Fort }\end{array}$ & $\begin{array}{l}0 \\
0 \\
0\end{array}$ & $\begin{array}{l}0 \\
0 \\
0\end{array}$ & $\begin{array}{l}0 \\
0\end{array}$ & $\begin{array}{r}0 \\
80 \\
150\end{array}$ & $\begin{array}{r}0 \\
80 \\
215\end{array}$ \\
\hline
\end{tabular}

TABLEAU 2

Stades physiologiques pour le prélèvement des plantes. Physiological stages for plant sampling.

\begin{tabular}{|c|c|}
\hline Cultures & Stades physiologiques \\
\hline Blé & $\begin{array}{l}\text { Fin tallage (f.TAL) } \\
\text { Montaison (MONT) } \\
\text { Epiaison (EPI) } \\
\text { Floraison (FLO) } \\
\text { Grain laiteux (GL) }\end{array}$ \\
\hline Colza & $\begin{array}{l}\text { Début montaison (d.MONT) } \\
\text { Apparition inflorescence (FLO) } \\
\text { Début remplissage graines (d.R.GR.) } \\
\text { Fin remplissage graines (f.R.GR.) }\end{array}$ \\
\hline Féverole & $\begin{array}{l}\text { Bouton floral (BF) } \\
\text { Floraison (FLO) } \\
\text { Allongement des gousses (A.GS.) } \\
\text { Remplissage des graines (R.GR.) }\end{array}$ \\
\hline Soja & $\begin{array}{l}\text { Stade végétatif } 6^{\mathrm{e}} \text { feuille trifoliolée (V6) } \\
\text { Pleine floraison (p.FLO.) } \\
\text { Allongement des gousses (A.GS.) } \\
\text { Remplissage des graines (R.GR.) }\end{array}$ \\
\hline Tournesol & $\begin{array}{l}\text { Bouton floral (BF) } \\
\text { Début floraison (FLO) } \\
\text { Début chute des pétales (d.CP.) } \\
\text { Remplissage des graines (R.GR.) }\end{array}$ \\
\hline
\end{tabular}

- fort : rendement élevé recherché $(85 \mathrm{q} / \mathrm{ha}$ pour le blé) pour chaque culture de la succession avec le minimum de risques, irrigation satisfaisant les besoins en eau des différentes espèces, fertilisation supérieure aux exportations, traitements phytosanitaires préventifs.
Les différenciations des niveaux d'intensification sont indiquées dans le tableau 1.

Les prélèvements, les analyses de feuilles et les mesures d'activité photosynthétique ont été effectués, pour chaque espèce, aux stades de développement indiqués dans le tableau 2. Ils concernent, dans tous les cas, les limbes des feuilles situés sur le haut du couvert.

\section{B. Techniques analytiques}

Toutes les déterminations présentées ci-dessous ont été faites sur 3 répétitions.

L'extraction des protéines solubles a été réalisée sur $5 \mathrm{~g}$ de limbes, homogénéisés à l'aide d'un broyeur à hélice (Omnimixer Sorvall ; vitesse maximale ; $5 \times$ 30 secondes) dans $20 \mathrm{ml}$ du milieu (Tris- $\mathrm{HCl} 0,1 \mathrm{M}$, pH 7,5 ; EDTA $1,5 \mathrm{~m} \mathrm{M}$; DDT $10 \mathrm{~m} \mathrm{M}$; PEG 6000 , $6 \mathrm{~g} / 1$; polyclar AT, 10 p. 100 du matériel végétal). L'homogénat est centrifugé (Beckman J2-21; $30000 \times \mathrm{g} ; 15 \mathrm{~min})$ puis filtré. Le filtrat constitue l'extrait protéique brut sur lequel sont effectués :

- le dosage des protéines solubles selon la méthode de LOWRY modifiée par BENSADOUN \& WEINSTEIN (1976) ;

- la mesure in vitro de l'activité carboxylasique de la RuBisCO selon la technique radiochimique de RAAGHAVENDRA \& DAS (1977). L'activité mesurée dans ces conditions correspond aux potentialités maximales du pool enzymatique présent dans le végétal ;

- le dosage de la RuBisCO à l'aide de la technique de dosage immunochimique par électrophorèse (LAURELL, 1966 ; COURTIADE, 1983) grâce à des anticorps 
dirigés contre la RuBisCO de tournesol. Il a été vérifié que la protéine enzymatique des différentes espèces étudiées était reconnue par les anticorps « tournesol ».

Les mesures de photosynthèse nette in situ (échanges gazeux au niveau de la feuille) sont réalisées le même jour que les analyses en laboratoire, au cours de journées bien ensoleillées sur des feuilles adultes situées au sommet du couvert. Un dispositif analogue à celui de NAYLOR \& TEARE (1975), modifié par N. GELFI (I.N.R.A. Auzeville), et couplé à un analyseur différentiel de $\mathrm{CO}_{2}$ à infrarouge (Leybold, Heraeus, Type Binos) a été utilisé pour ces déterminations effectuées sous la concentration naturelle en $\mathrm{CO}_{2}$ de l'air en vérifiant la température, l'humidité relative et l'éclairement. La quantité de $\mathrm{CO}_{2}$ fixée est déterminée d'après la différence des teneurs de l'air entre l'entrée et la sortie de la chambre contenant le fragment de limbe.

Les mesures de photosynthèse et les prélèvements pour le dosage in vitro ont été effectués entre $8 \mathrm{~h}$ et $11 \mathrm{~h}$ TU.

La teneur en azote total des feuilles a été déterminée après minéralisation et sans réduction des nitrates, selon la méthode de KJELDHAL (cité par CHARLOT, 1961).
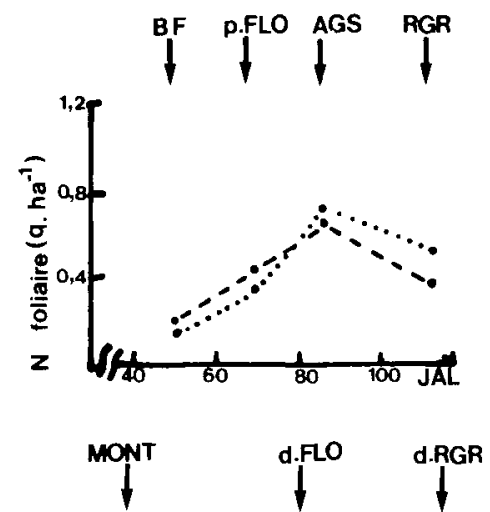

FEVEROLE

B
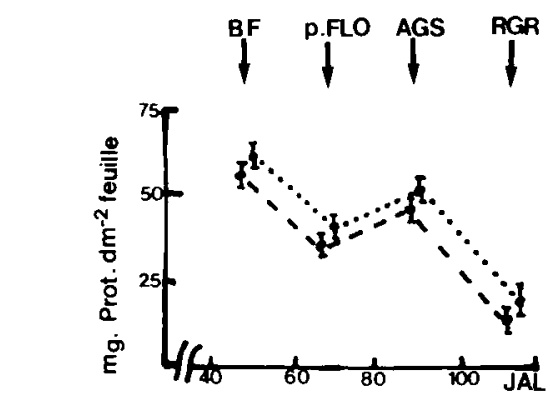

COLZA

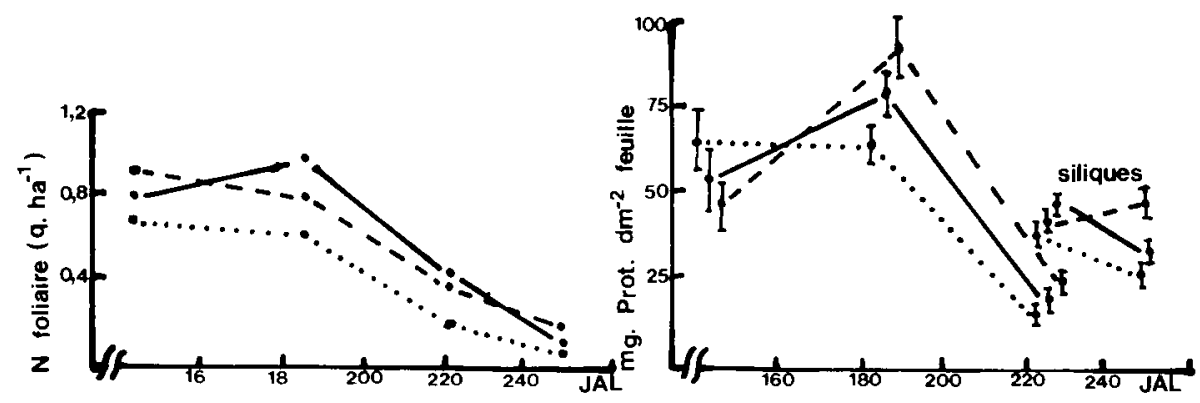

BLE
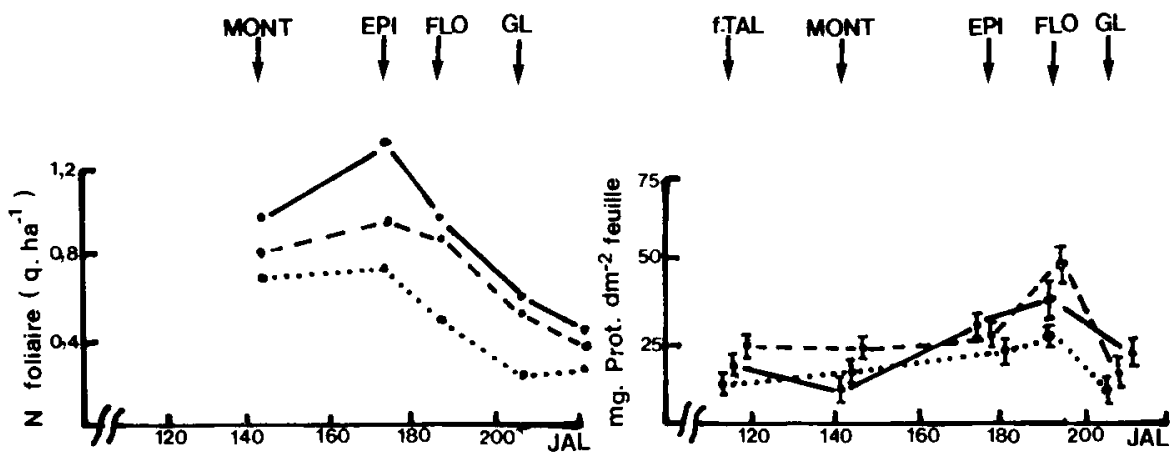

Figure 1

Evolution de la quantité d'azote total foliaire exprimé en $q \cdot \mathrm{ha}^{-1}(A)$ et de la teneur en protéines solubles en $\mathrm{mg} . \mathrm{dm}^{-2}$ de surface foliaire $(B)$ des feuilles de cultures d'hiver conduites à différents

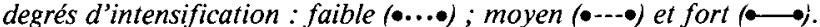
Limites de confiance à $95 \%$ (\$). Détails des stades physiologiques dans le tableau 2. J.A.L. = Jours après levée.
Total leaf $N$ content $100 \mathrm{~kg} . \mathrm{ha}^{-1}(\mathrm{~A})$ and amount of soluble proteins, $m g . d m^{-2}$ of leaf area $(B)$ in leaves of winter crops at different input levels : low $(\bullet . . . \bullet)$; medium $(\bullet-. . \bullet)$ and high $(\bullet-)$. Details of physiological stages in table 2. J.A.L. = Days after emergence. 


\section{RÉSULTATS}

\section{A. Teneurs en azote et en protéines solubles des feuil- les}

Les figures 1 et 2 mettent en évidence que les intensifications moyenne et forte des cultures d'hiver conduisent, en général, à des teneurs en azote foliaire plus élevées; cependant, des différences sensibles selon les espèces sont observées.

Chez le blé et le colza, il y a une bonne relation, pendant une grande partie du cycle de développement, entre la teneur en azote total des feuilles et le niveau d'intensification. Cependant en fin de végétation, le taux d'azote foliaire est identique quelle que soit l'intensification.

Chez la féverole, légumineuse qui ne reçoit pas d'engrais azotés, l'influence des traitements sur le taux d'azote foliaire est moins nette. Chez le soja, les intensifications moyenne et forte, conduisent à des teneurs en azote foliaire élevées principalement au stade de l'allongement des gousses ; par contre, dans l'intensification la plus faible, la teneur en azote est basse pendant toute la croissance de la culture. De plus, comme chez les autres espèces, en fin de culture, les 3 traitements présentent une teneur en azote total analogue. Il faut souligner que les niveaux d'intensification du soja diffèrent principalement par l'irrigation, l'azote provenant dans tous les cas de la fixation symbiotique et des
A
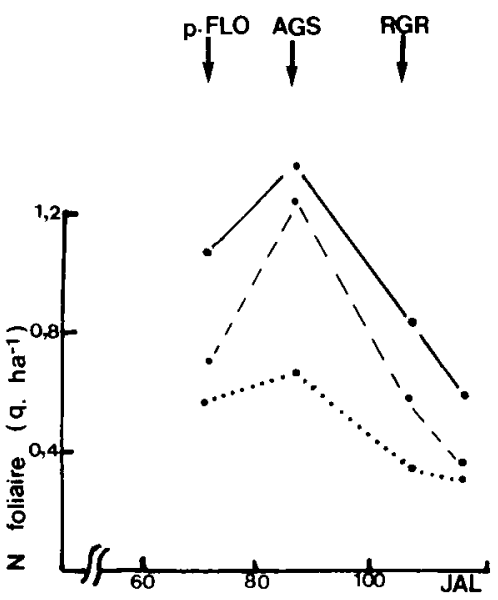

B

SOJA
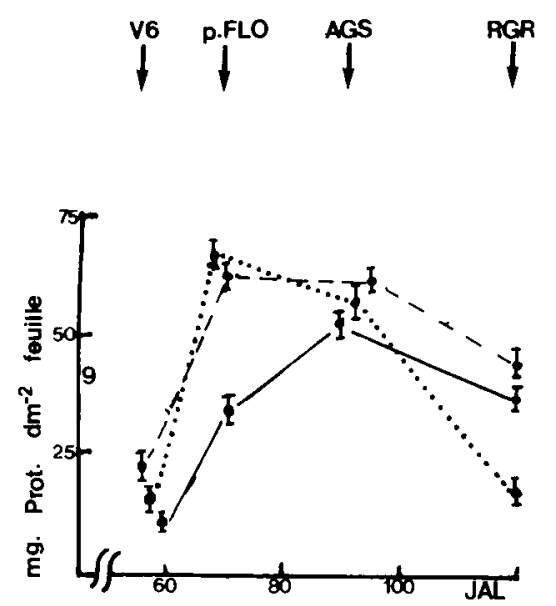

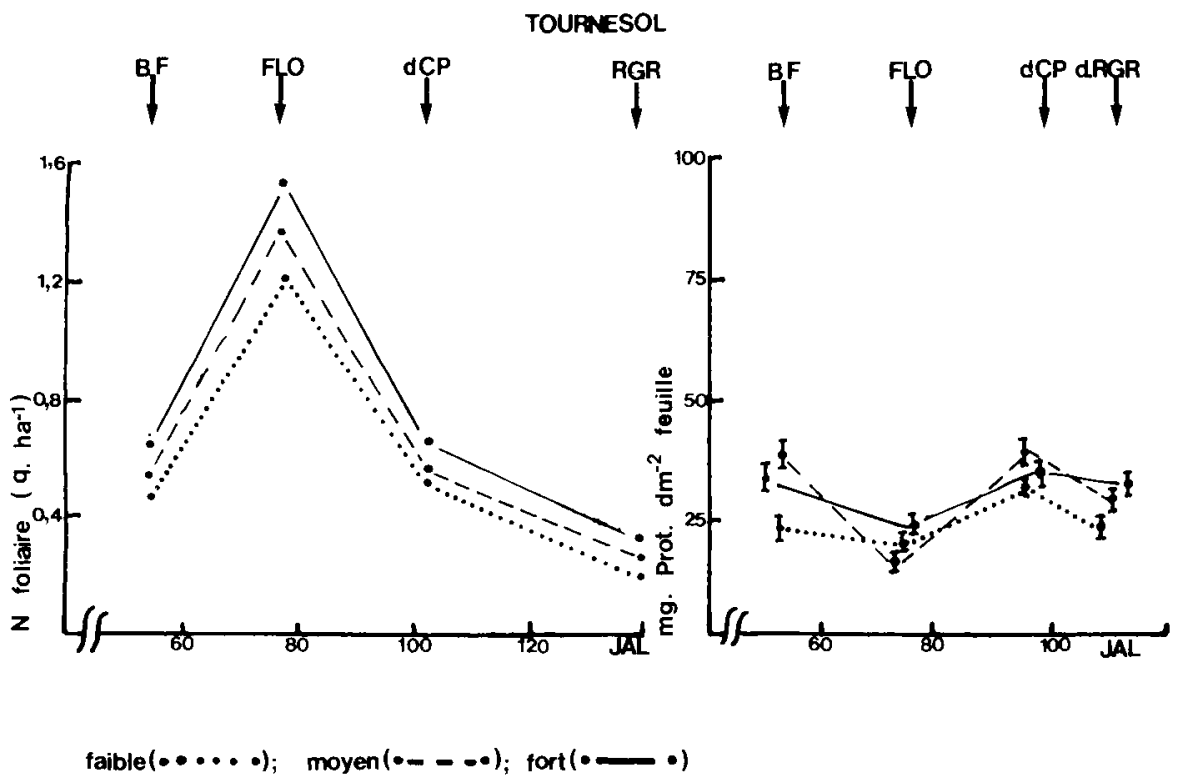


réserves minérales du sol ; le régime hydrique exerce donc une influence prépondérante sur l'azote foliaire. Chez le tournesol, il n'y a pas de variations importantes entre les différents niveaux d'intensification.

En ce qui concerne les protéines solubles, l'effet des niveaux d'intensification est moins marqué que dans le cas de l'azote foliaire. Rapportées à l'unité de surface de limbe, les teneurs les plus faibles concernent le blé et le tournesol, et elles varient peu au cours du cycle de végétation. Chez le colza et le soja, la quantité de protéines solubles augmente fortement au début de la floraison pour diminuer ensuite rapidement pendant la période de remplissage des graines.

\section{B. Teneur et activité RuBisCO}

Les teneurs des feuilles en RuBisCO évoluent de manière identique à celles des protéines solubles. A l'exception du colza qui présente des quantités d'enzyme de carboxylation 2 à 3 fois plus élevées dans le cas des intensifications moyenne et forte (apport de fumure notamment), la teneur en RuBisCO semble peu influencée par les différents traitements appliqués (fig. 3A et 4A). Par contre l'activité de l'enzyme varie selon les intensifications (fig. $3 B$ et $4 B$ ). En général, les intensifications moyenne et forte conduisent à des activités carboxylasiques plus marquées que l'intensifica-

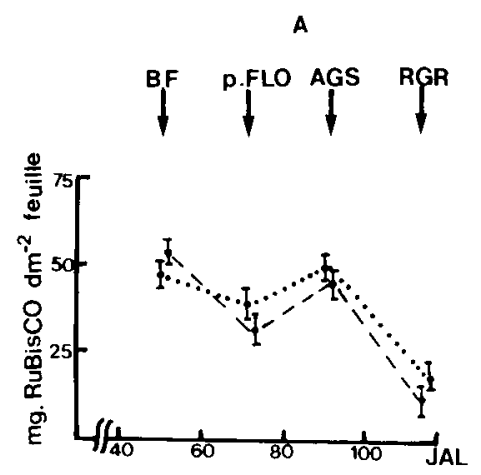

FEVEROLE

\section{B}

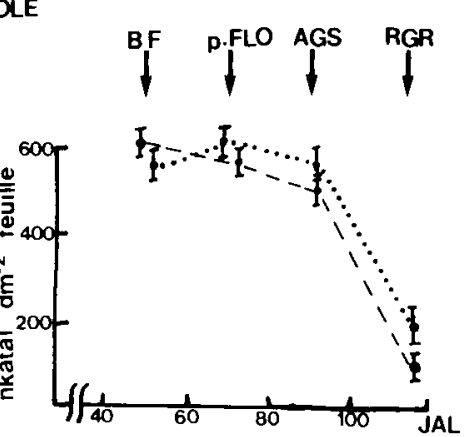

COLZA

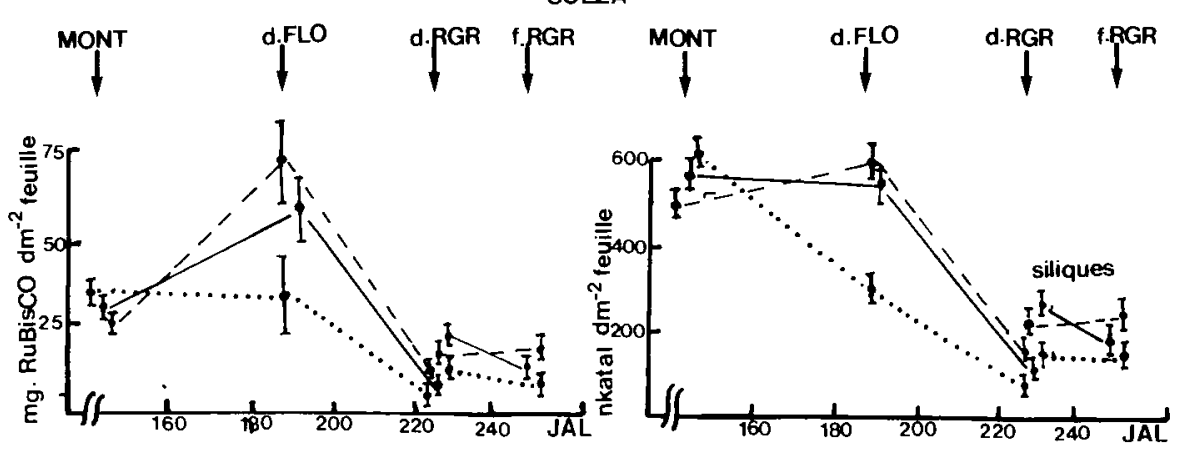

BLE
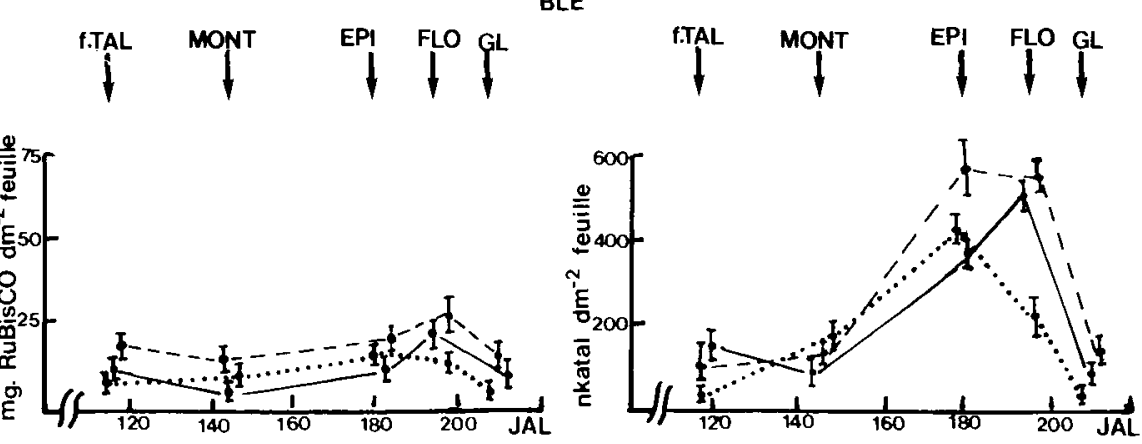

faible $(\cdots \cdots \cdot \ldots \cdot \cdot) ;$ moyen $(\bullet---\bullet)$; fort $(\bullet-\bullet)$

Figure 3

Evolution de la teneur en RuBisCO en $\mathrm{mg} . \mathrm{dm}^{-2}$ de surface foliaire $(A)$ et de l'activité RuBisCO en nkatal $\mathrm{dm}^{-2}$ surface foliaire $(B)$ des feuilles de cultures d'hiver conduites à différents degrés d'intensification. (Détails des symboles dans la fig. I et le tabl. 2.)
RuBisCO content, mg. $\mathrm{dm}^{-2}$ of leaf area (A) and RuBisCO activity nkatal $\mathrm{dm}^{-2}$ of leaf area $(B)$ in leaves of winter crops at different input levels. (Details of symbols in fig. 1 and table 2.) 
tion faible. Malgré une teneur faible, l'enzyme des feuilles de blé développe une forte activité dès la floraison. De plus, à la baisse de la teneur en RuBisCO (à partir du stade allongement de gousses chez la féverole, ou après le stade début floraison chez le colza), correspond une diminution importante de son activité. Chez le soja soumis à un déficit hydrique (intensification faible), l'activité $\mathrm{RuBisCO}$ est fortement réduite.

\section{Photosynthèse nette}

Les résultats concernant les mesures d'assimilation sont présentés dans la figure 5. Ces mesures effectuées à différentes périodes de l'année rendent compte des capacités de fixation de $\mathrm{C}$ sous des conditions d'environnement variables : cependant, l'éclairement mininum était de 160 watt. $\mathrm{m}^{-2}$, la teneur en $\mathrm{CO}_{2}$ voisine de $320 \mathrm{vpm}$. Il apparaît que les cultures d'hiver ont entre elles des niveaux voisins de photosynthèse nette (de 10 à $20 \mathrm{mg}$ de $\dot{\mathrm{C}} \mathrm{O}_{2} \mathrm{dm}^{2}$ feuille/heure). En revanche, pour les cultures d'été, les activités photosynthétiques sont 1,5 fois plus élevées chez le soja irrigué (au stade allongement des gousses) et 3,5 fois plus chez le tournesol (en début de période reproductive). Toutefois, il faut souligner que pour les différentes espèces, l'activité photosynthétique diminue brusquement au moment de la floraison (au début floraison pour colza, blé, tournesol ou à la fin floraison pour soja et féverole).

La très forte activité de la feuille de tournesol confirme les observations déjà effectuées chez ce végétal. Ainsi au stade bouton floral, la photosynthèse nette est de $60 \mathrm{mg} \mathrm{de} \mathrm{CO}_{2}$ fixé $/ \mathrm{dm}^{2}$ feuille/heure et de $30 \mathrm{mg}$ pour des stades ultérieurs, soit le taux de fixation généralement rencontré chez les plantes $\mathrm{C} 4$.

Chez les cultures d'été, l'activité photosynthétique est sensible aux modifications des itinéraires techniques : les intensifications moyenne et forte conduisent à des activités photosynthétiques plus élevées ; le soja
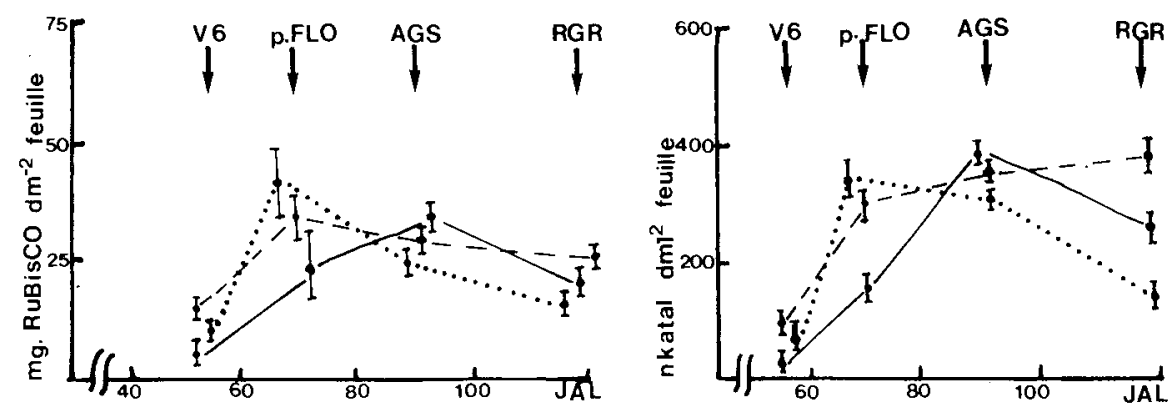

TOURNESOL
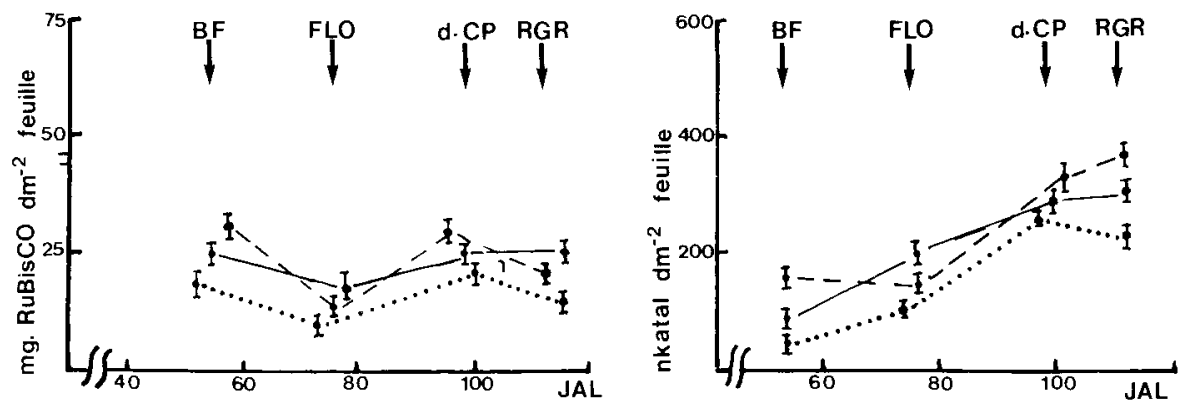

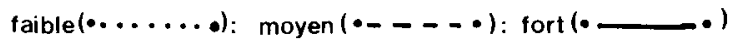



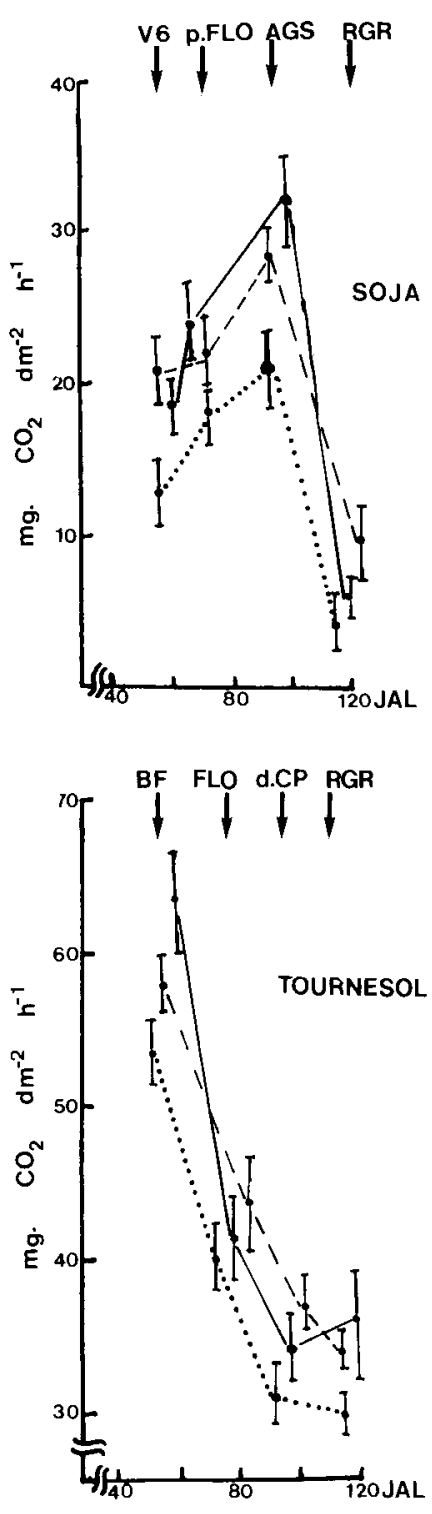

CULTURES ETE

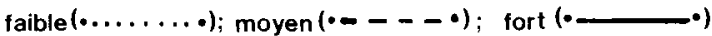
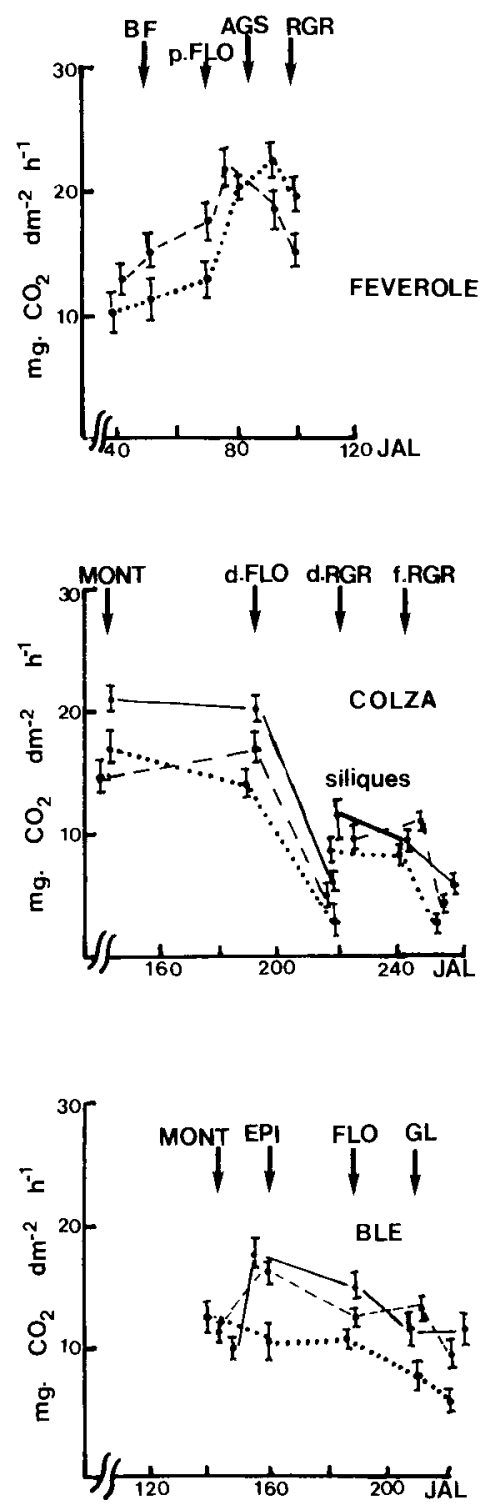

CULTURES HIVER
Figure 5

Evolution de la photosynthèse nette, en $\mathrm{mg} \mathrm{CO} \mathrm{CO}_{2} \mathrm{dm}^{-2} \cdot h^{-1}$, des feuilles de cultures d'hiver et d'été conduites à différents degrés d'intensification. (Détails des symboles dans la fig. I et le tabl. 2.)

non irrigué (intensification faible) présente une activité photosynthétique réduite dès le début du cycle de végétation. Il semble donc, dans cette culture, que la privation d'eau, bien qu'elle n'ait pas d'incidence notoire sur la teneur en enzyme ait des répercussions préjudiciables à l'activité carboxylasique potentielle et à la photosynthèse nette.

Dans les cultures d'hiver, il y a, avec les intensifications moyenne et forte, une augmentation significative de la photosynthèse nette entre montaison et épiaison chez le blé, entre montaison et début floraison chez le colza et du stade bouton floral à la pleine floraison chez la féverole.

En conséquence, l'itinéraire technique joue un rôle important sur la photosynthèse nette jusqu'au stade de pleine floraison, ensuite vient le déclin accompagnant la maturation.
Net photosynthesis $\left(\mathrm{CO}_{2} \mathrm{mg} . \mathrm{dm} \mathrm{m}^{-2} \cdot \mathrm{h}^{-1}\right)$ in leaves of winter and summer crops at different input levels. (Details of symbols in fig. $I$ and table 2.)

\section{Rendement}

En général, les rendements obtenus à la suite des intensifications moyenne et forte sont peu différents (tabl. 3). Par contre, ils sont supérieurs à ceux obtenus pour l'intensification faible ; les pertes de rendement comparativement aux deux autres traitements sont respectivement de 19 et 38 p. 100 pour le colza et le blé et de 12 et 35 p. 100 pour les cultures d'été (tournesol et soja). Ces résultats confirment que la fertilisation des cultures d'hiver et l'irrigation chez les cultures d'été conduisent à des augmentations de rendement.

\section{DISCUSSION ET CONCLUSION}

Dans nos conditions expérimentales, l'intensification culturale augmente la teneur en azote des feuilles, mais 
TABLEAU 3

Rendements aux normes agricoles obtenus dans les cultures conduites à différents degrés d'intensification.

Crop yield under agricultural standard conditions obtained at different levels of inputs.

\begin{tabular}{|c|c|c|c|}
\hline \multirow{2}{*}{ Cultures } & \multirow{2}{*}{$\begin{array}{c}\text { Niveau } \\
\text { d'intensification }\end{array}$} & \multicolumn{2}{|c|}{ Rendements } \\
\hline & & $\mathrm{qha} \mathrm{h}^{-1}$ & $\begin{array}{c}\% \mathrm{du} \\
\text { niveau fort }\end{array}$ \\
\hline Blé & $\begin{array}{l}\text { Faible } \\
\text { Moyen } \\
\text { Fort }\end{array}$ & $\begin{array}{l}47,3 \\
74,5 \\
76,2\end{array}$ & $\begin{array}{r}62 \\
98 \\
100\end{array}$ \\
\hline Colza & $\begin{array}{l}\text { Faible } \\
\text { Moyen } \\
\text { Fort }\end{array}$ & $\begin{array}{l}27,2 \\
32,6 \\
33,7\end{array}$ & $\begin{array}{r}81 \\
97 \\
100\end{array}$ \\
\hline Féverole & $\begin{array}{l}\text { Faible } \\
\text { Moyen }\end{array}$ & $\begin{array}{l}36,4 \\
40,5\end{array}$ & $\begin{array}{r}90 \\
100\end{array}$ \\
\hline Soja & $\begin{array}{l}\text { Faible } \\
\text { Moyen } \\
\text { Fort }\end{array}$ & $\begin{array}{l}22,8 \\
35,2 \\
33,2\end{array}$ & $\begin{array}{r}69 \\
107 \\
100\end{array}$ \\
\hline Tournesol & $\begin{array}{l}\text { Faible } \\
\text { Moyen } \\
\text { Fort }\end{array}$ & $\begin{array}{l}33,9 \\
37,3 \\
38,7\end{array}$ & $\begin{array}{r}88 \\
96 \\
100\end{array}$ \\
\hline
\end{tabular}

influence peu la teneur en protéines solubles. Ainsi, par exemple, les cultures maintenues sous une faible intensification (apport $\mathrm{N}$ faible chez le blé et le colza) présentent des teneurs en azote foliaire peu élevées, alors que la quantité de protéines solubles par unité de surface de limbe reste proche de celles observées dans les autres cas d'intensification.

Au début du cycle de végétation, il n'existe pas de liens très étroits entre les apports azotés (caractéristiques des intensifications moyenne et forte du blé, du colza et du tournesol) et les teneurs en protéines solubles des feuilles. Les différences les plus sensibles apparaissent à la floraison, notamment chez le blé et à un degré moindre chez le tournesol : une protéolyse plus intense, notamment de la $\mathrm{RuBisCO}$, chez les végétaux les moins bien pourvus pourrait expliquer ce fait (fig. 3A et 4A). Les acides aminés ainsi libérés pourraient être remobilisés au profit des graines ce qui aurait pour effet d'atténuer le déficit de l'alimentation en azote à partir du sol.

Il est en général difficile d'établir une relation nette entre le taux d'activité photosynthétique de la feuille et le rendement comme l'ont déjà souligné les auteurs cités par ELMORE (1980) ; toutefois c'est en cherchant à étudier la réponse aux différentes situations culturales de la RuBisCO, enzyme fixatrice du $\mathrm{CO}_{2}$ chez les plantes $\mathrm{C} 3$, que l'on pourrait appréhender les blocages de la bioconversion de l'énergie lumineuse en produit utile. Dans nos conditions d'expérimentation de Toulouse-Auzeville, il apparaît :

- d'une part, qu'il y a souvent peu de différence dans les paramètres étudiés entre les intensifications moyenne et forte mais qu'elles se distinguent de l'intensification faible,

- d'autre part, que c'est à certains stades physiologiques : début floraison (blé, colza) ou fin floraison début formation du fruit (féverole, soja, tournesol) que l'on observe des évolutions comparables de la photosynthèse nette, de l'activité $\mathrm{RuBisCO}$ et du rendement obtenu. Ainsi, pour l'intensification moyenne du blé ou du colza, à des teneurs plus importantes de protéines solubles et de RuBisCO correspond l'augmentation des activités carboxylasique et photosynthétique.

En ce qui concerne la culture en condition sèche ou irriguée du soja, les variations entre les paramètres sont de plus grande amplitude. Elles se traduisent notamment par une diminution très marquée des teneurs en protéines solubles et en RuBisCO dès le stade pleine floraison, ainsi qu'une activité carboxylasique et une activité photosynthétique significativement moindres. Cette influence du régime hydrique peut s'exercer notamment à travers la distribution des assimilats et la fourniture d'azote provenant du sol ou de la symbiose (BounIOLs et al., 1985).

Chez le tournesol, l'intensification culturale (apports d'eau et de fumure) ne crée pas de distinctions marquées, car cette culture est capable d'explorer les couches plus profondes du sol par son système racinaire (MAERTENS \& BOSC, 1981).

Toutefois, la très forte activité photosynthétique (notamment chez le tournesol) ne peut pas être attribuée à des différences de teneurs en enzyme. Par exemple, l'activité potentielle (in vitro) de la RuBisCO du tournesol varie en raison inverse de la photosynthèse nette (fig. 4B et 5) ; il faut donc supposer un système de régulation de l'activité enzymatique in vivo. Cependant, la méthode utilisée pour mesurer l'activité in vitro (après activation de l'enzyme par le $\mathrm{CO}_{2}$ et du $\mathrm{Mg}^{2+}$ ) conduit à l'expression de toutes les formes présentes in vivo. Or, PERCHOROWICZ \& JENSEN (1983) ont noté que l'activation de la $\mathrm{RuBisCO}$ dépend non seulement de $\mathrm{Mg}^{2+}$ et des variations du $\mathrm{pH}$ du stroma $\mathrm{du}$ chloroplaste, mais aussi de la teneur en ribulose bisphosphate susceptible de se fixer à l'enzyme. Chez plusieurs espèces, il semble qu'une grande partie de la RuBisCO à l'obscurité soit en état d'inactivation et insensible au $\mathrm{CO}_{2}$ et au $\mathrm{Mg}^{2+}$ (Vu et al., 1984). Par contre, celle-ci peut être activée quand la feuille est exposée à la lumière (SERvaites et al., 1984). De même, SHARKEY et al. (1986) ont relié l'efficacité de l'enzyme à sa liaison à un inhibiteur ; en effet, SERVAITES (1985) a suggéré que l'inactivation était due à la fixation d'un composé phosphorylé sur l'enzyme. Récemment, ce composé a été identifié au 2-carboxyarabinitol-1-phosphate (GUTTERIDGE et al., 1986) et le degré d'inhibition est variable selon les espèces (SERVAITES et al., 1986).

Bien que limités à quelques conditions culturales, ces premiers résultats incitent à poursuivre l'analyse des relations entre la photosynthèse nette, l'évolution de la teneur et de l'activité de la RuBisCO et le rendement de la culture, en prenant en compte les stades physiologiques, la régulation in vivo de la $\mathrm{RuBisCO}$ et le rythme circadien de l'activité RuBisCO.

Reçu le 25 novembre 1986. Accepté le 27 mai 1987.

\section{REMERCIEMENTS}

Ce travail a bénéficié du soutien financier du Ministère de la Recherche et de l'Enseignement Supérieur. Les auteurs remercient vivement le Dr. R. BLANCHET pour ses conseils et sa contribution à la réalisation de cette étude, ainsi que M. PIQuemal, Mme Borderies, A. Hilaire, P. Rozelle, M. Mondies et J. Laurent pour leur collaboration. 


\section{RÉFÉRENCES BIBLIOGRAPHIQUES}

Bensadoun A., Weinstein D., 1976. Assay of proteins in the presence of interfering materials. Anal. Biochem., 70, 241-250.

Blanchet R., Gelfi N., Piquemal M., Amiel C., 1986. Influence de l'alimentation azotée sur l'évolution de l'assimilation nette au cours du cycle de développement du tournesol (Helianthus annuus L.). C. R. Acad. Sci., Paris, 302, Série III, (5), 171-176.

Bouniols A., Puech J., Chalamet A., Mondies M., 1985. Influence des conditions d'alimentation hydrique ou (et) azotée à différents stades du développement sur la production de grains et la nutrition azotée du soja. Eurosoya, 3, 55-61.

Charlot G., 1961. Les méthodes de la chimie analytique. Masson Edit., 611-613.

Courtiade B., 1983. La ribulose biphosphate carboxylase oxygénase du tournesol; dosage et évolution ontogénique. Thèse Université Paul Sabatier, Toulouse, $63 \mathrm{p}$.

Ellis R. J., 1979. The most abundant protein in the world. Trends in Biol. Sci., 4, 241-244.

Elmore C. D., 1980. The paradox of no correlation between leaf photosynthesis rates and crop yields. In HESKETH J., JONES D., WeDIT J. Predicting photosynthesis for ecosystem models. C.R.C. Press, 155-167.

Evans J. R., Seemann J. R., 1984. Differences between wheal genotypes in specific activity of ribulose-1,5-bisphosphate carboxylase and the relationship to photosynthesis. Plant Physiol., 74, 759-765.

Gutteridge S., Parry M. A. J., Burton S., Keys A. J., Mudd A., Feeney J., Servaites J. C., Pierce J., 1986. A nocturnal inhibitor of carboxylation in leaves. Nature 324, 274-276.

Hesketh J. D., Ogren W. L., Hageman M. E., Peters D. B., 1981. Correlations among leaf $\mathrm{CO}_{2}$-exchange rates, areas and enzyme activities among soybean cultivars. Photosynthesis Res., 2, 21-30.

Laurell C. B., 1966. Quantitative estimation of proteins by electrophoresis in agarose gel containing antibodies. Anal. Biochem., 15, 45-52.

Mächler F., Nösberger J., 1980. Regulation of ribulose bisphosphate carboxylase activity in intact wheat leaves by light, $\mathrm{CO}_{2}$, and temperature. J. Exp. Bot., 31, 1485-1491.

Maertens C., Bosc M., 1981. Etude de l'évolution de l'enracinement du tournesol. Bull. Techn. CETIOM, 273, 1, 3-10.

Makino A., Mae T., Ohira K., 1983. Photosynthesis and ribulose-1,5-bisphosphate carboxylate in rice leaves. Plant Physiol., 73, 1002-1007.

Marty J. R., Hutter W., Rellier J. P., 1981. Projet de programme de recherches expérimentales sur l'optimisation des intrants dans des rotations avec céréales et oléoprotéagineux avec ou sans irrigation. In Optimisation des intrants dans un système de culture. Séminaire C.E.E., Agrimed. Toulouse, janvier 1981, 119-131.

Marty J. R., Cabelguenne M., Puech J., 1984a. Perspective de valorisation d'un milieu par des assolements de grandes cultures: Essais d'optimisation technico-économiques. I : Elaboration d'un modèle de choix d'assolement. Agronomie, 4, 871-884.

Marty J. R., Cabelguenne M., Puech J., 1984b. Perspectives de valorisation d'un milieu par des assolements de grandes cultures : Essais d'optimisation technico-économiques. II : Exemples d'assolements, résultats techniques et agronomiques. Agronomie, 4 915-925.

Naylor D. G., Teare I. D., 1975. An improved rapid field method to measure photosynthesis with ${ }^{14} \mathrm{CO}_{2}$. Agron. J., 67, 404-406.

Perchorowicz J. T., Jensen R. G., 1983. Photosynthesis and activation of ribulose biphosphate carboxylase in wheat seedlings. Plant physiol., 71, 955-960.

Pyke K. A., Leech R. M., 1985. Variation in ribulose-1,5 bisphosphate carboxylase content in a range of winter wheat genotypes. J. Exp. Bot., 36, 1523-1529.

Raaghavendra A. S., Das V. S., 1977. Purification and properties of PEPCase and RuDPCase C4 and C3. Z. Pflanzenphysiol., 82, 315321.

Servaites J., 1985. Binding of a phosphorylated inhibitor to ribulose bisphosphate carboxylase/oxygenase during the night. Plant Physiol., 78, 839-843.

Servaites J. C., Torisky R. S., Shih F. C., 1984. Diurnal changes in ribulose-1,5-bisphosphate carboxylase activity and activation state in leaves of field growth soybeans. Plant Sci. Lett., 35, 115-121.

Servaites J. C., Parry M. A. J., Gutteridge S., Keys A. J., 1986. Species variation in the predawn inhibition of ribulose-1,5-bisphosphate carboxylase/oxygenase. Plant Physiol., 82, 1161-1163.

Sharkey T. D., Seemann J. R., Berry J. A., 1986. Regulation of ribulose-1,5-bisphosphate carboxylase activity in response to changing partial pressure of $\mathrm{O}_{2}$ and light in Phaseolus vulgaris. Plant Physiol., 81, 788-791.

Torisky R. S.. Servaites ,I. C., 1984. Effect of irradiance during growth of Glycine max. on photosynthetic capacity and percent activation of ribulose-1,5-bisphosphate carboxylase. Photosynthesis Res., 5, 251-261.

Vu J. C. V., Allen L. M., Bowes G., 1984. Dark/light modulation of ribulose bisphosphate carboxylase activity in plants from different photosynthetic categories. Plant Physiol., 76, 843-845. 